\title{
IR Spectroscopic Characterization of Lignite as a Tool to Predict the Product Range of Catalytic Decomposition
}

\author{
Valentin Cepus*, Markus Borth, Mathias Seitz \\ Department Engineering and Natural Sciences, Merseburg University of Applied Sciences, Merseburg, Germany \\ Email: *valentin.cepus@hs-merseburg.de
}

Received 28 November 2015; accepted 20 February 2016; published 23 February 2016

Copyright (C) 2016 by authors and Scientific Research Publishing Inc.

This work is licensed under the Creative Commons Attribution International License (CC BY). http://creativecommons.org/licenses/by/4.0/

c) (i) Open Access

\begin{abstract}
The catalytic pyrolysis of lignites is a technical process whose development is complex and timeconsuming with the goal to maximize the yield of the desired low-volatile hydrocarbons of choice and to minimize the yield of solid residual products. Not every type of lignite is suitable for this process due to its particular chemical composition. In order to be able to predict which lignite specimen will be an especially promising raw material for the pyrolytic liberation of target products, the chemical classification by IR spectroscopic methods was investigated. MIR spectroscopy has been demonstrated to be a valuable tool to characterize the the molecular composition of lignites and to determine the concentrations of aliphatic and aromatic functional groups in lignite as well as alcoholic $\mathrm{OH}$ and other forms of bound oxygen. These data provide a comprehensive chemical characterization of the material and help to predict the composition of the chemical components liberated by catalytic decomposition. With a complementary NIR spectroscopic approach, a chemometric method has been developed with which the elemental composition of the lignites can be determined in a fast and pragmatic way leading to a prediction of the product range of a theoretical pyrolytic product range. Thus, this spectroscopic investigation is a toolbox that can answer the question if the commercial exploitation of catalytic pyrolysis of a lignite sample in question will make sense without preliminary conduction of long and time-consuming testing.
\end{abstract}

\section{Keywords}

Coal, Lignite, IR Spectroscopy, Characterization, MIR, NIR, Pyrolysis

\footnotetext{
${ }^{*}$ Corresponding author.
}

How to cite this paper: Cepus, V., Borth, M. and Seitz, M. (2016) IR Spectroscopic Characterization of Lignite as a Tool to Predict the Product Range of Catalytic Decomposition. International Journal of Clean Coal and Energy, 5, 13-22. 


\section{Introduction}

The raw materials coal and lignite contain an enormous potential for the supply of precious products in the chemical industry. The conversion of coal, which is a complex mixture of compounds, by a catalytic pyrolytical process yields the possibility to liberate liquid and gaseous hydrocarbons among other types of compounds that can be applied with high technical versatility. The conversion of coal and lignite by combination of chemical processes will thus be important for the future supply with educts and intermediates in the chemical industry. These special applications require optimized variants of combinations of the reaction system catalyst-coal for the efficient substantial exploitation. The following results and discussions have been collected by catalytic conversion of southeastern German lignites. From former experimental investigations, it is known that the catalyst zeolith ZSM-5 releases a maximum yield of unsaturated low-molecular hydrocarbons [1] [2].

In order to predict the product spectrum of such a catalytic conversion, it is important to characterize the lignites as raw materials of these processes. This has been achieved by infrared spectroscopic (IR) investigations with local lignites. The evaluation comprises a well-defined choice of representative lignites from open-cast mining "Vereinigtes Schleenhain" and "Amsdorf". For a first classification, the division into light and dark lignites is proved to be appropriate. Middle infrared (MIR) spectroscopy permits the definition of constitutional preconditions for suitable types of lignites. Besides the questions of raw material quality, the knowledge of the correlation between the IR spectrum of lignite tar and lignite coke with the chosen process parameters is of vital importance. Furthermore, the correlation between the quantitative determination of elemental composition with characterization in near infrared (NIR) has to be investigated. By identification of the characteristic spectroscopic information, the properties of the raw materials and anticipated product yield and quality after pyrolysis should thus be employed for an optimized exploitation of lignites.

\section{Materials and Methods}

IR spectroscopic investigation of lignite in MIR (middle infrared) range required some sample preparation as pulverization in a mortar. 5 to $8 \mathrm{mg}$ lignite was mixed with $1 \mathrm{~g}$ of $\mathrm{KBr}$ (for IR spectroscopy) and milled in an agate mortar. 5 spatula of this mixture were put into a $13 \mathrm{~mm}$ pelleting tool and pressed for $10 \mathrm{~min}$ at a load of 10 tons with a hydraulic press. For the preparation of tar $15 \mathrm{mg}$ of this highly viscous liquid were dissolved in 2 $\mathrm{ml}$ of dichloromethane. $1 \mathrm{~g}$ of $\mathrm{KBr}$ were mixed with $300 \mu \mathrm{l}$ of the dichloromethane solution, milled in an agate mortar, heated for $2 \mathrm{~min}$ in an oven at $50^{\circ} \mathrm{C}$ before pressing to a pellet as described above [3].

IR measurements were conducted with a Thermo Nicolet Avatar 360 FT-IR spectrometer with DTGS detector. The IR spectra were recorded between 4000 and $400 \mathrm{~cm}^{-1}$ with a resolution of $8 \mathrm{~cm}^{-1}$ and coaddition of 32 scans in transmission mode. Acquisition of all measurements was conducted in triplicate. The recorded spectra were converted into absorbance spectra and baseline corrected. Data processing and calculations were performed with the spectroscopy software "OMNIC". The fitting processes were employed as described elsewhere [4].

For NIR (near infrared) spectra the sample preparation was different. Pure samples and calibration mixtures were milled in a mortar and homogenized in a shaker for $20 \mathrm{~min}$. The spectra were recorded on a Thermo Nicolet Nexus NIR spectrometer with a fibre-optic probe head in diffuse reflexion mode and an InGaAs detector between 4000 and $10,000 \mathrm{~cm}^{-1}$ at a spectral resolution of $8 \mathrm{~cm}^{-1}$ with accumulation of 128 scans and measured in triplicates. Calculation of the fit model with PLS regression was conducted using the software TQ Analyst.

To determine the hydrocarbon yield of different lignite samples with different compositions, a discontinuous rotary kiln was used, described elsewhere [1]. At standard reaction conditions (inert, $400^{\circ} \mathrm{C}$, ZSM- 5 powder as catalyst with modulus 240 and a catalyst to lignite (maf) ratio of 1:20), a mixture of lignite and catalyst was charged into the pre heated reactor. The volatile products pass a filter where tar is deposited. Condensable products were detained in two traps cooled at $0^{\circ} \mathrm{C}$ and $-196^{\circ} \mathrm{C}$. The product gases and liquids streams were measured and analyzed by IR spectroscopy and gas chromatography. The yield of hydrocarbons in the range of one to nine carbon atoms was used as a measure to quantify high quality products.

\section{Results and Discussion}

\subsection{Characterization of Raw Lignites with MIR Spectroscopy}

The comparison of FTIR spectra of different lignite samples from open-cast mining "Schleenhain” (Figure 1) shows several spectroscopic features that can be found in all IR spectra. These comprise a broad O-H-stretching 


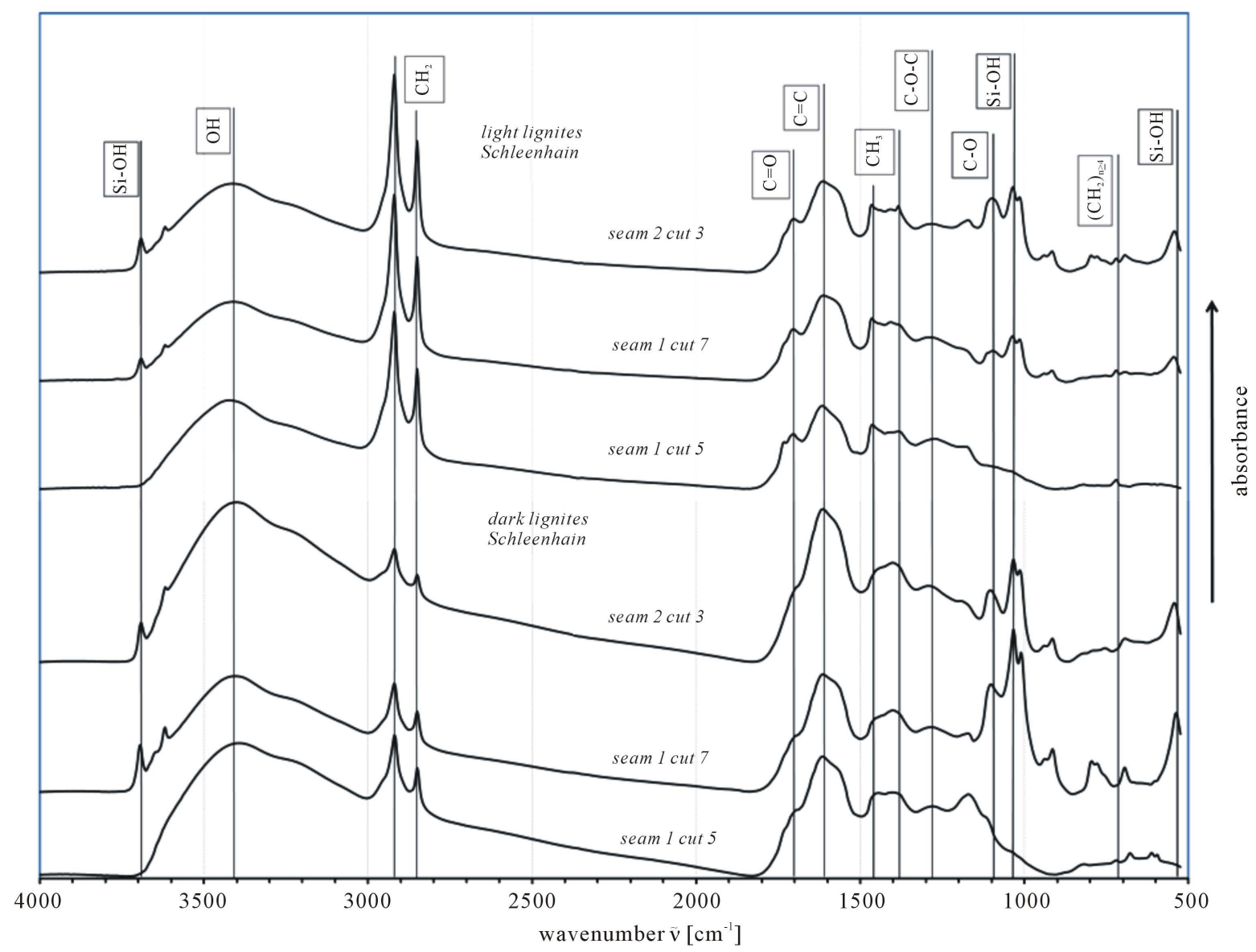

Figure 1. FTIR spectra of lignite from open cast mining “Schleenhain”, comparison of light and dark Southeastern German lignites from different seams.

vibration at $3400 \mathrm{~cm}^{-1}$ of hydrogen bridges, $\mathrm{C}$-H-stretching vibration of methylene groups between 3000 and $2800 \mathrm{~cm}^{-1}, \mathrm{C}=\mathrm{O}$ and $\mathrm{C}=\mathrm{C}$ stretching vibrations around 1700 and $1600 \mathrm{~cm}^{-1}$, and C-O-C/C-O vibrations at $1280 / 1090 \mathrm{~cm}^{-1}$, respectively [5]. In contrast to this only in a part of the measured IR spectra the signal of the SiO-H and Si-OH stretching vibrations around 3700 to $3600 \mathrm{~cm}^{-1}$ and $1040 \mathrm{~cm}^{-1}$ can be detected [6]-[8]. Although the basic structure element of lignites is based on aromatic rings, no indication of an absorption band between 3100 to $3000 \mathrm{~cm}^{-1}$ of the aromatic C-H stretching vibration is found which gives a hint to a network structure in which most of the aromatic hydrogen atoms are substituted.

The comparison between the light and dark lignite samples shows that light lignites exhibit a more pronounced absorption between 3000 and $2800 \mathrm{~cm}^{-1}$, revealing more aliphatic methylene groups than dark lignites. In contrast to this dark lignites show a stronger absorption at $1600 \mathrm{~cm}^{-1}$ which can be referred to aromatic C-C double bonds. In the lower wave number region light lignites show an absorption band at $720 \mathrm{~cm}^{-1}$ that is caused by out of plane deformation of at least 4 consecutive methylene groups hinting to longer-chain aliphatic units for light samples in contrast to dark samples where this absorption is not identified.

A closer investigation has been conducted with respect to the range of the aliphatic C-H stretching vibrations in the range between 3000 and $2800 \mathrm{~cm}^{-1}$ by deconvolution of the IR spectra as shown in Figure 2. The asymmetric and the symmetric $\mathrm{CH}_{2}$ stretching vibrations at $2921 \mathrm{~cm}^{-1}$ and $2850 \mathrm{~cm}^{-1}$ lead to absorption bands with the highest observed absorbances. The resulting values for the absorbance of light lignites are twice as high as that of the dark lignites (Figure 3). The strong absorption bands of light lignites correlate with a higher observed yield of volatile hydrocarbons by pyrolysis of light lignites. Thus, a tendency towards higher alkane and alkene yield can be concluded from the presence of strong bands of $\mathrm{CH}_{2}$ stretching vibrations. A more quantitative evaluation of the pyrolytic process can be achieved by integration of the areas of the deconvoluted bands at 2850 


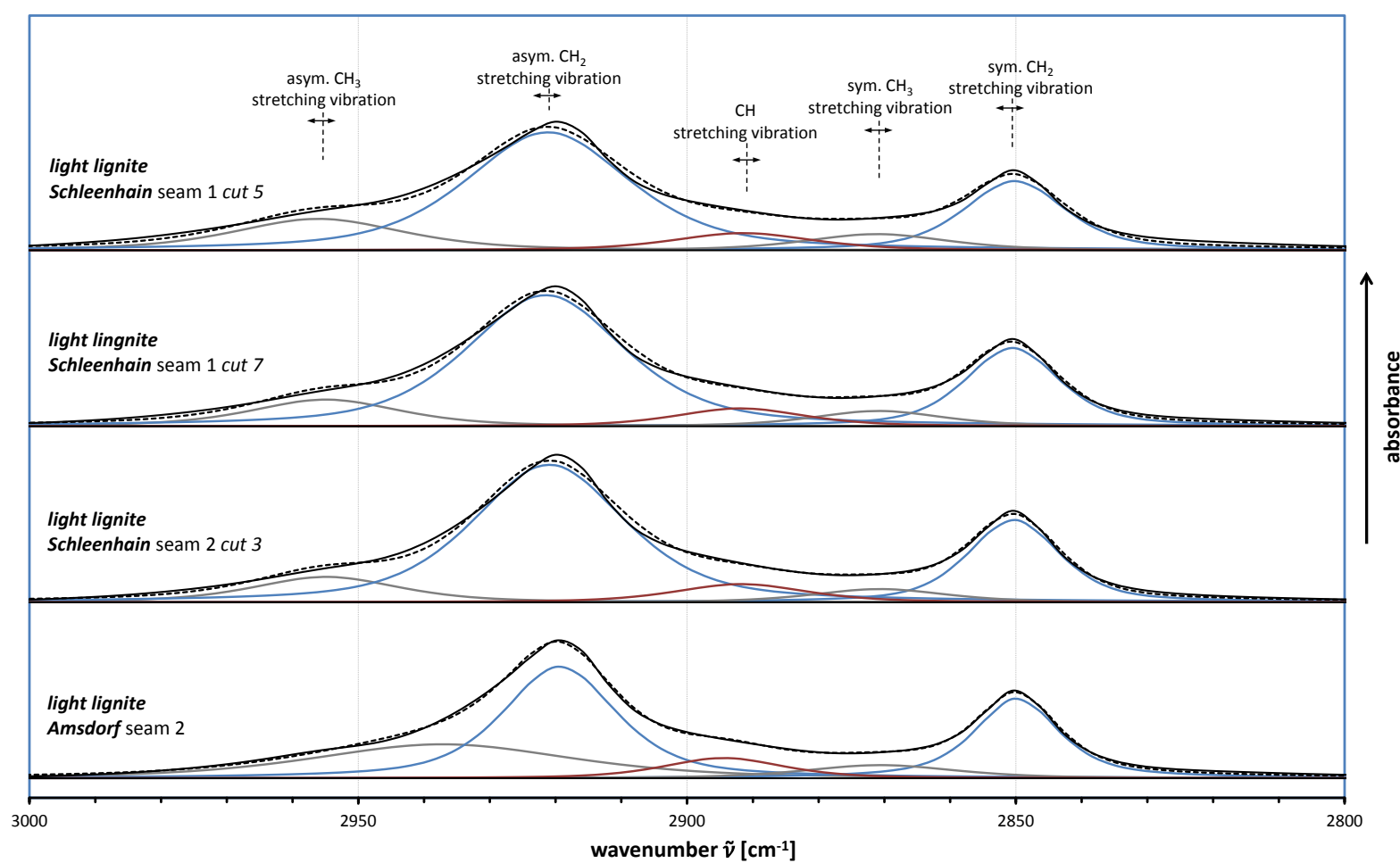

Figure 2. FTIR spectra of light lignite with Gauss-Lorentz deconvolution function bands contributing to the spectrum of the sample. Total spectrum — deconvoluted spectrum _---, methylene bands _ —, methyl bands _ —, methine bands —.

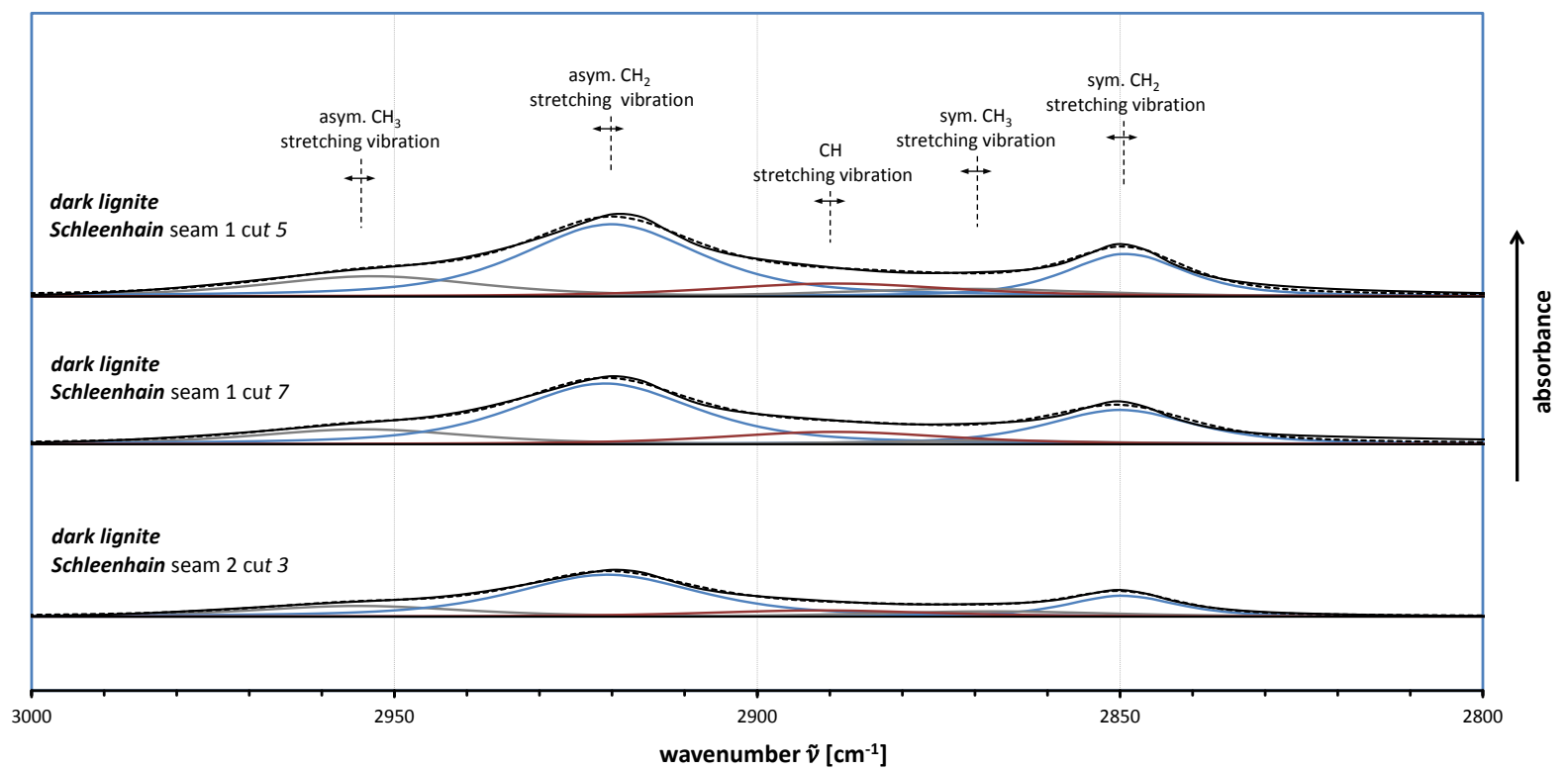

Figure 3. FTIR spectra of dark lignite with Gauss-Lorentz deconvolution function bands contributing to the spectrum of the

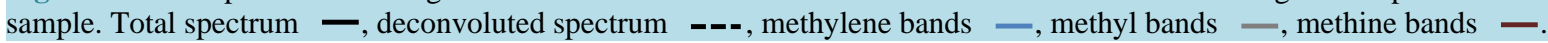

$\mathrm{cm}^{-1}$ and $2921 \mathrm{~cm}^{-1}$. For the light lignite "Schleenhain" of seam 2, the calculated areas of the spectrum hint to the highest yield among all investigated lignites and are in agreement with experimental results by pyrolysis. A yield of $11.8 \%$ waf (referring to water and ash free lignites) of saturated and unsaturated hydrocarbons in the range of one to nine carbon atoms could be achieved by pyrolysis of this type of lignite. In contrast to this by the conversion of dark lignite "Schleenhain" of seam 2 only a yield of 3.7\% waf could be isolated. 
In addition to the relatively broad absorption bands of methylene in this wavenumber interval, several relatively broad bands of asymmetric and symmetric $\mathrm{CH}_{3}$ stretching vibrations at $2955 \mathrm{~cm}^{-1}$ and $2870 \mathrm{~cm}^{-1}$ can be observed. It can be derived that $\mathrm{CH}_{3}$ absorption bands of light lignites are slightly stronger than of dark lignites. The absorbance of methine groups at $2890 \mathrm{~cm}^{-1}$ hints to the degree of branching of aliphatic molecular contributions in the lignite structure.

In the spectral region between 1800 and $1000 \mathrm{~cm}^{-1}$ a multitude of absorption can be detected which can be roughly assigned to categories of specific functional groups.

In Figure 4 this lower specific spectral region is explored for light lignites. For the characterization of structural changes of carbonyl compounds the fitted bands between $1645-1750 \mathrm{~cm}^{-1}$ are investigated [5]. The band pattern of all lignite spectra show at least three pronounced absorption bands of the carbonyl groups. Especially for light lignites a band can be detected at $1735 \mathrm{~cm}^{-1}$ that can be referred to aromatic esters. The band at 1705 $\mathrm{cm}^{-1}$ with the highest intensity in this region hints to the presences of carboxylic functions. Especially for the lignites from "Amsdorf" a rather complex structure of carbonyl compounds is expected due to the numerous bands that could be differentiated by deconvolution for this sample. The absorbance at $1650 \mathrm{~cm}^{-1}$ has been tentatively assigned to different aromatic ketones. The determination of aromatic structures has been supported by observations in the spectral region between $1500-1630 \mathrm{~cm}^{-1}$ standing for the $\mathrm{C}=\mathrm{C}$ stretching vibration. Especially the absorption at $1615 \mathrm{~cm}^{-1}$ exhibits a stable value and in conjugation with $\mathrm{C}=\mathrm{O}$ this band becomes strong and broad. By increasing carbonization there is the tendency of an increasing absorbance of this band which furthermore correlates with a higher coke yield. For the wavenumber region between 1365 and $1475 \mathrm{~cm}^{-1}$ spectra are recorded with characteristic signals of aliphatic C-H bending vibrations. The absorbance bands at 1460 $\mathrm{cm}^{-1}$ and $1375 \mathrm{~cm}^{-1}$ can be assigned to bending vibrations of the $\mathrm{CH}_{3}$ group. In comparison to the bands of $\mathrm{CH}_{2}$ bending relative ratios can be calculated to explain the degree of branching.

\subsection{MIR Characterization of Pyrolysis Products}

Furthermore, the IR spectra of the raw lignite samples and the products of the pyrolytic process, coke and tar, are shown in Figure 5. The comparison between lignite and coke shows a noticeable agreement with respect to

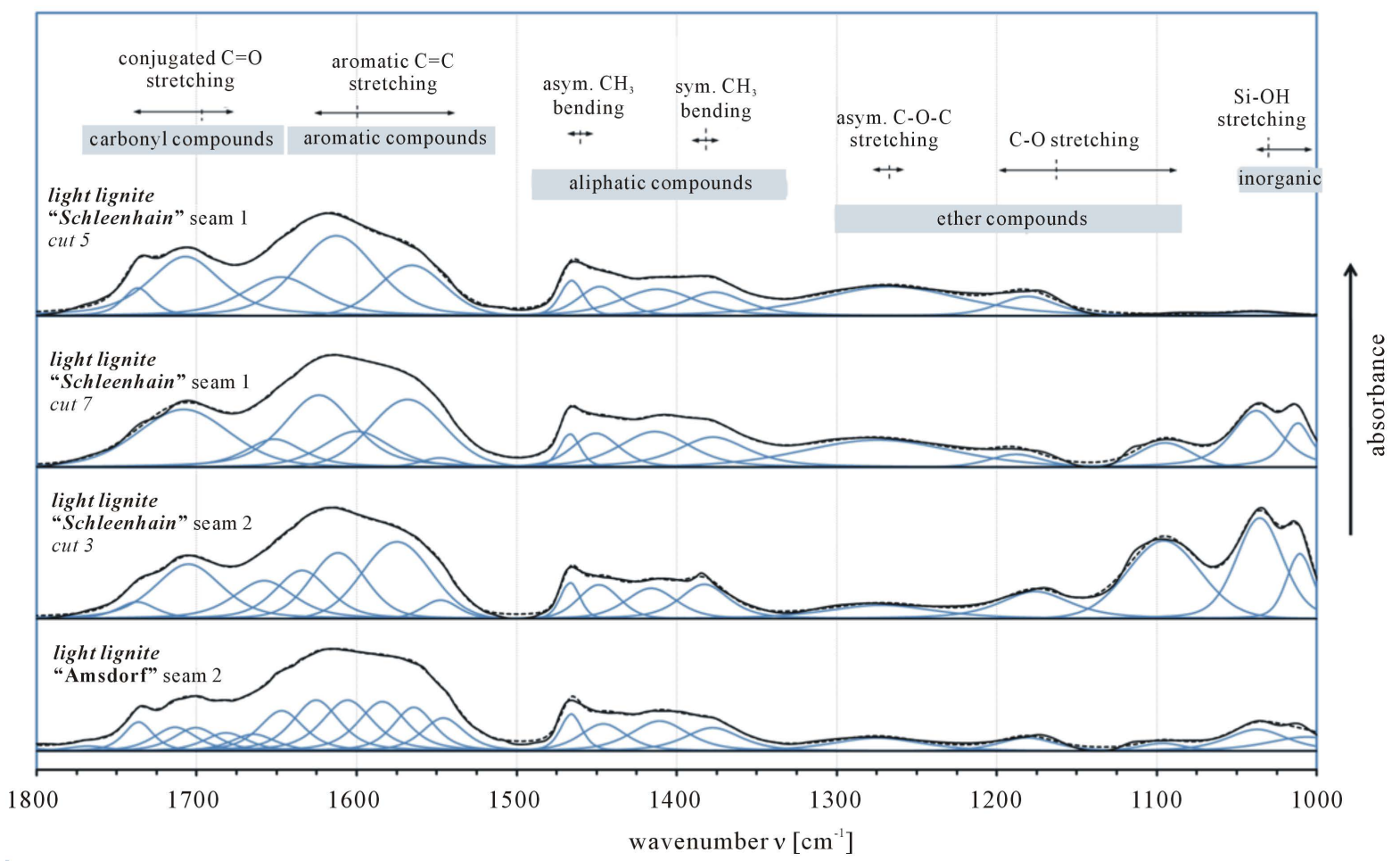

Figure 4. FTIR spectra of light lignite with Gauss-Lorentz deconvolution functions contributing to the spectrum of the sample. Total spectrum —, deconvoluted spectrum - ---, contributing bands of functional groups - - . 


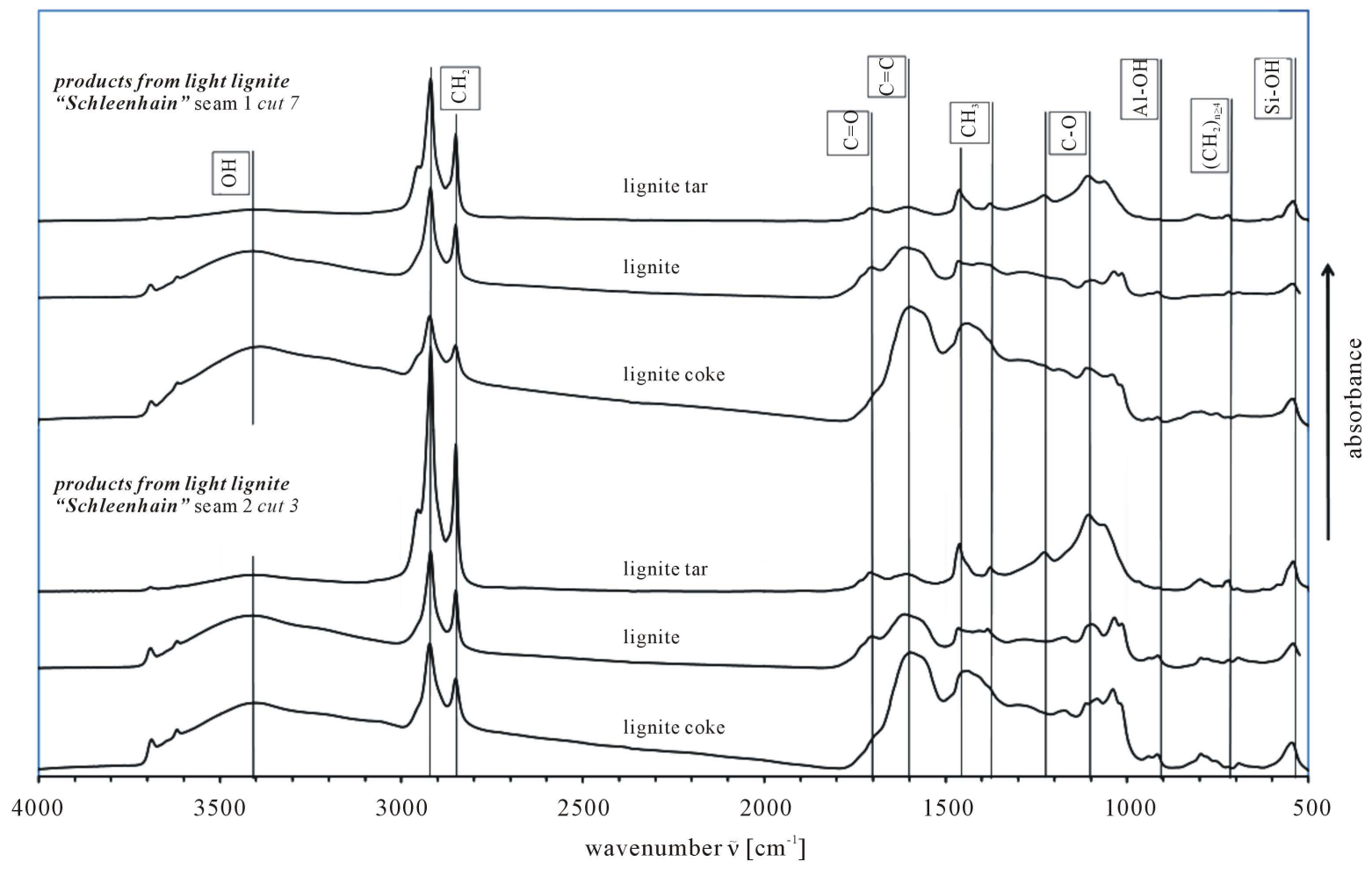

Figure 5. FTIR spectra of tar and coke from catalytic conversion of light lignites "Schleenhain" with zeolith ZSM-5, comparison with products and utilized raw lignites.

the pattern of the aromatic absorption bands. The intensity of the band of the carboxylic functional group at $1705 \mathrm{~cm}^{-1}$ is remarkably weaker in the spectrum of tar than in the spectrum of lignite and is hardly observable in the spectrum of the coke. Thus, we can determine a lower amount of carbonyl and carboxylic groups in tar than in lignite. Similar band patterns that have been recognized in IR spectra of the utilized lignite samples are also observable in the IR band pattern of the products. By comparison of these spectra a successful assignment of the functional groups can be achieved. In the spectral region between 1500 and $1630 \mathrm{~cm}^{-1}$ the characteristic stretching vibrations of the $\mathrm{C}=\mathrm{C}$ groups highlight the complex aromatic constitution of coke.

This individual band pattern represents the highly aromatic state of the released coke, which is in agreement with the chemical structure documented in literature [9]. In contrast to this, the IR spectra of tar only show a broad band with low intensity at $1610 \mathrm{~cm}^{-1}$, hinting to low amounts of aromatic compounds. The IR absorbance bands below $1500 \mathrm{~cm}^{-1}$ reveal the aliphatic $\mathrm{CH}$ bending vibrations. At $1465 \mathrm{~cm}^{-1}$ the asymmetric $\mathrm{CH}_{3}$ bending vibration can be observed [8]. Due to the increase of this band it can be derived that tar from lignite of seam 2 contains a higher concentration of $\mathrm{CH}_{3}$ groups. In general, the absorption of this $\mathrm{CH}_{3}$ bending vibration appears as narrow intensive band in the spectrum of tar and lignite. As an additional spectral feature, the intensive and broad absorption in the region between 1050 and $1150 \mathrm{~cm}^{-1}$ is dominated by C-O stretching vibrations. Due to the simultaneous presence of the $\mathrm{O}-\mathrm{H}$ stretching vibrations at $3400 \mathrm{~cm}^{-1}$ these bands can be assigned to the absorption bands of secondary alcohols. Thus, lignite tar contains a higher concentration of secondary alcohols than lignite coke. Furthermore it can be derived that the concentration of secondary alcohols in tar from lignite of seam 1 is higher. For the further characterization of phenol containing compounds the absorption at 1170 $\mathrm{cm}^{-1}$ has been investigated. This band is very pronounced for the lignite sample of seam 2 . The conversion products also exhibit this absorption band, which is, however, a bit lower than for lignite. With rising concentration of phenol in the aqueous phase a decrease of this band can be observed in the IR spectrum of coke. For the band at $1035 \mathrm{~cm}^{-1}$ of the $\mathrm{Si}-\mathrm{OH}$ stretching vibration which hints to the presence of inorganic silicate minerals, similar intensity of the signals are observable for the IR spectra of coke and the respective lignite sample out of which the coke was converted [10]. The lack of this band in the IR spectra of tar shows that there is no silicate mineral present in the produced tar. 


\subsection{NIR Chemometric Characterization of Raw Lignites}

As NIR spectroscopy is a powerful tool for the chemometric characterization of complex mixtures this technique seems to be adequate for the aim of a fast method for evaluation of lignites being a promising raw material for catalytic conversion [11]. A time consuming approach for such a characterization is the elemental analysis of C, $\mathrm{O}$, and $\mathrm{H}$ in raw lignites. For this purpose, a calibration has been conducted of 30 individual samples mixed with 5 different reference lignite samples that contain known concentrations of the named elements. For the chemometric calculations, all calibration samples were measured in triplicate in order to obtain an appropriate amount of data points. A set of 30 typical exemplary NIR spectra of investigated calibration samples are recorded of which one example is shown in Figure 6.

For the calculation of the concentration of carbon and hydrogen the whole set of untreated NIR spectra of the calibration references was utilized. Primarily the spectral region between 4310 and $5880 \mathrm{~cm}^{-1}$ contained the necessary information. This region is dominated by the absorption of the $\mathrm{CH}_{3}$ groups as well as by overtones of the $\mathrm{C}=\mathrm{O}$ group. In Figure 7 and Figure 8 the correlation diagrams between the NIR spectroscopic determination of the elemental composition and the results of the elemental analysis are shown. It can be revealed that the elemental composition of lignites can be predicted by an NIR based calibration model. Especially for the elements $\mathrm{C}$ and $\mathrm{H}$ the prediction is accurate. However, it can be observed that the current fit model leads to an underestimation of the oxygen content, especially for the external samples. This difference can be explained by the fact that for the elemental analysis the determination of oxygen is a calculated result based on the balance calculation referring to the elemental analysis of $\mathrm{C}, \mathrm{N}, \mathrm{H}$. Furthermore, the exact water content of lignites might affect the absorbance at $5200 \mathrm{~cm}^{-1}$. This wavenumber is used for the determination of oxygen bound in carbonyl form.

\section{Conclusion}

\section{Prediction of the Hydrocarbon Yield}

For the production of hydrocarbons, the hydrocarbon yield of the catalytic pyrolysis of lignites depends strongly from the molar $\mathrm{H} / \mathrm{C}$ and $\mathrm{O} / \mathrm{C}$ ratio. Especially, lignites with a high $\mathrm{H} / \mathrm{C}$ ratio and a low oxygen content show the highest amount of desired product, while special types of lignites that are oxygen rich and hydrogen poor release only few liquid and gaseous products. As only few extraordinary lignites occur in nature, the hydrocarbon yield can be described only as a function of the $\mathrm{H} / \mathrm{C}$ ratio (Figure 9). Thus, the hydrocarbon yields of lignites with typical H/C ratios can be predicted well by NIR spectroscopy, even if the molar O/C ratio cannot be determined. As a result, NIR measurements can help to decide quickly, whether the lignite is suitable for hydrocarbon pro-

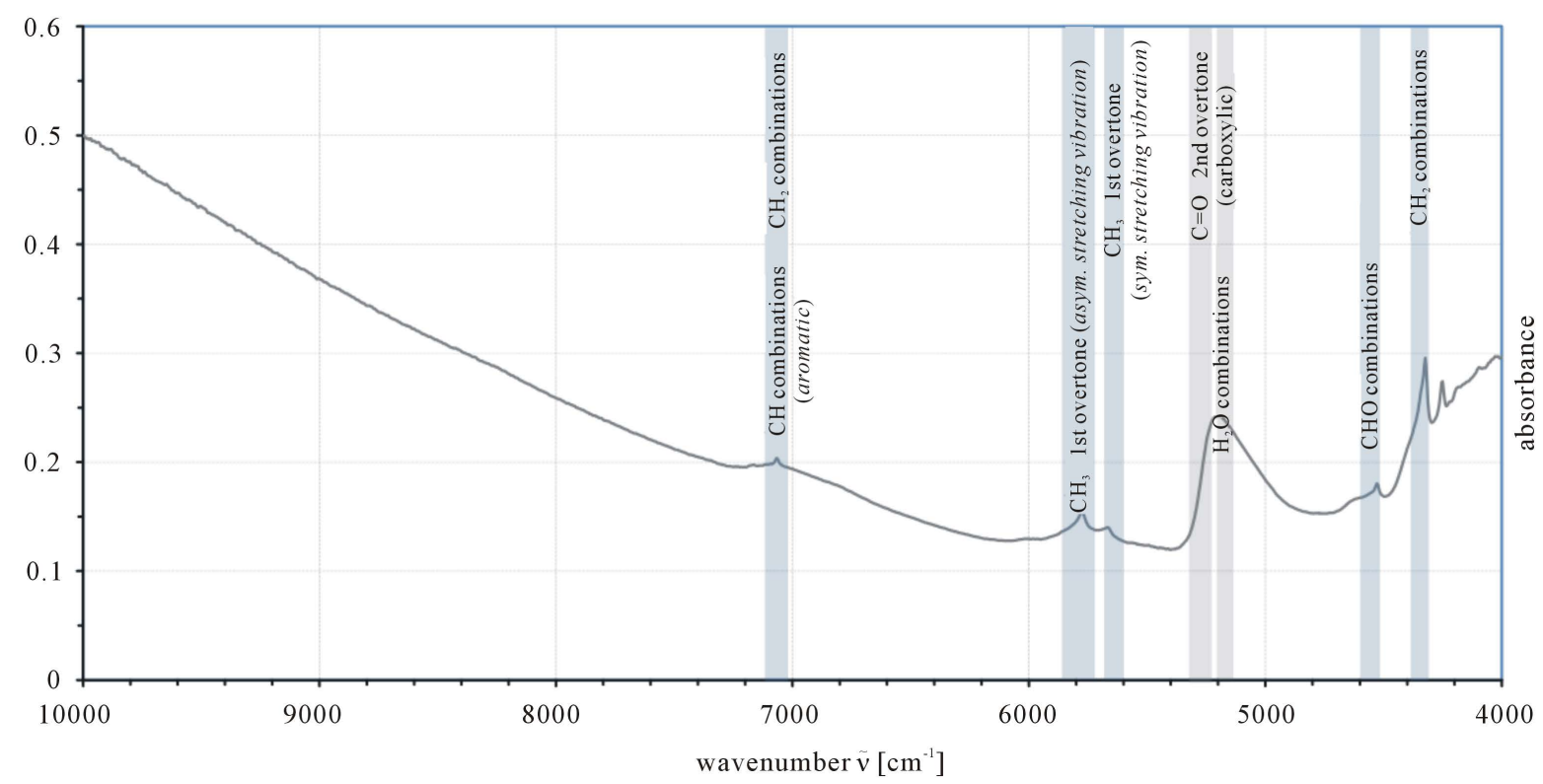

Figure 6. NIR spectrum of lignite calibration mixture based on dark lignite "Schleenhain” from seam 1 cut 7, example. 


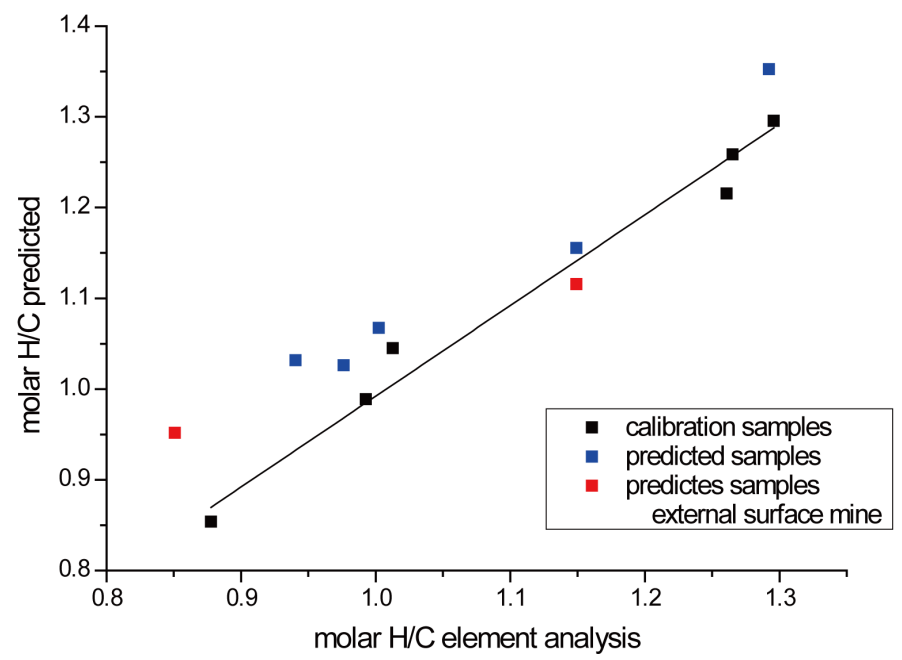

Figure 7. Correlation plot of the prediction of the molar $\mathrm{H} / \mathrm{C}$ ratio by the PLS fit model based on NIR spectroscopic data with reference values obtained by elemental analysis for the calibration mixture based on dark lignite "Schleenhain" from seam 1 cut 7.

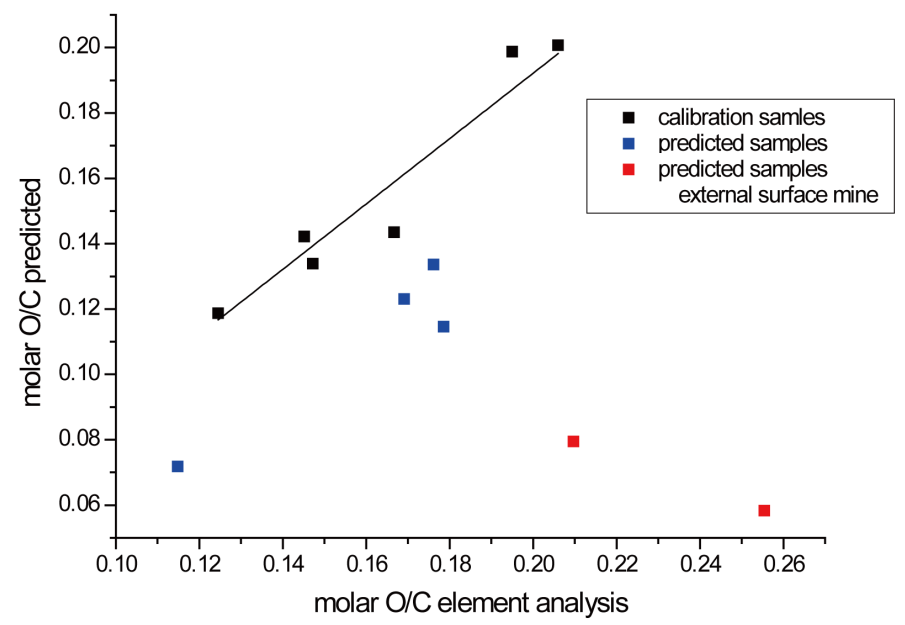

Figure 8. Correlation plot of the prediction of the molar $\mathrm{O} / \mathrm{C}$ ratio by the PLS fit model based on NIR spectroscopic data with reference values obtained by elemental analysis for the calibration mixture based on dark lignite "Schleenhain" from seam 1 cut 7.

duction with high yields of high-quality pyrolysis products.

\section{Summary}

The catalytic pyrolysis of lignites requires a technical refinement process with the goal to maximize the yield of desired low-volatile hydrocarbons and to minimize the yield of solid products. In order to achieve this target, the chemical composition of the incoming raw materials was characterized with MIR spectroscopy. As a complementary approach, the NIR chemometric determination of the elemental composition of carbon, hydrogen, and oxygen was established. It could be demonstrated that it is directly correlated to the product distribution of the pyrolytic products. For this, the chemical and elemental composition of the raw materials and the reaction products MIR and NIR methods have been developed that are applicable in a simple and pragmatic way.

Characteristic absorptions in the MIR spectra of the investigated raw lignites reveal the molecular constitution, for instance the aromatic and aliphatic character of the hydrocarbon backbone and important functional groups 


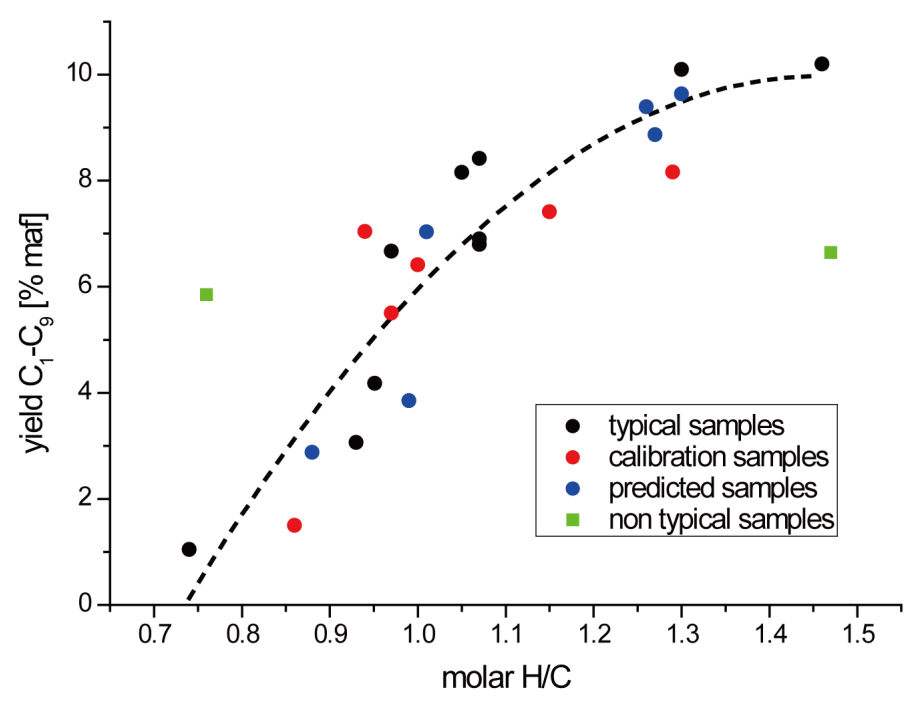

Figure 9. Low molecular hydrocarbon yield dependent of the molar $\mathrm{H} / \mathrm{C}$ ratio for the NIR calibration samples, the predicted samples by the PLS fit model and all samples investigated in pyrolysis; extraordinary lignites occur as outliers.

such as ketones, carboxylic acids, and alcohols. The characterization of the raw lignites showed that light lignite types contained a higher amount of aliphatic groups in contrast to dark types that showed a higher concentration of aromatic groups. This fact helps explaining the observed product spectra by catalysed pyrolytic conversion and helps to select lignite types that are promising with respect to commercially viable product yields upon catalytic decomposition.

Using the MIR spectroscopic toolbox for the understanding of the molecular constitution, also the products of the pyrolytic conversion process have been investigated. The characterization of the obtained lignite tars showed that they consist largely out of aliphatic hydrocarbons and of secondary alcohols and phenols. In contrast to this, the obtained coke products contain the majority of aromatic compounds as released by lignite. It can be shown that from lignite to coke the complexity of the aromatic structures increases. MIR characterization of raw lignites and of the pyrolysis products tar and coke can be employed as a straightforward tool for the understanding of the molecular constitution suitable for industrial use and for screening and prediction of lignites of high commercial value for catalytic conversion with zeolith ZSM-5.

By a chemometric approach based on an NIR spectroscopic calibration of samples with a known elemental composition of carbon, hydrogen and oxygen, the ratio of the concentration of hydrogen to carbon can be successfully predicted. The use of a fibre-optic ATR probe head leads to a very simple acquisition of NIR spectra. The time requirement for the duration of the measurement including milling and preparation process as well as result calculation does not exceed 10 minutes for one sample and can thus be considered as relevant and suitable for industrial application and replaces the time-consuming effort of conventional elemental analysis yielding to a substantial prediction of expectable hydrocarbon products by catalysed pyrolysis.

\section{Acknowledgements}

The authors gratefully acknowledge the financial support from Federal Ministry for Education and Research, Germany, and the MIBRAG for allocating the lignites with different elemental compositions, used in this work

\section{References}

[1] Seitz, M., Heschel, W., Nägler, T., Nowak, S., Zimmermann, J., Stam-Creutz, T., et al. (2014) Influence of Catalysts on the Pyrolysis of Lignites. Fuel, 134, 669-676. http://dx.doi.org/10.1016/j.fuel.2014.05.042

[2] Seitz, M., Nägler, T., Welscher, J., Nowak, S., Zimmermann, J., Hahn, T. and Schwieger, W. (2014) Catalytic Cracking of Lignites. Erdöl, Erdgas, Kohle, 130, 80-84. 
[3] Černý, J. (2007) Aliphatic C-H Bond Responses in the $900-700 \mathrm{~cm}^{-1}$ Region of the FTIR Spectra of Coal Tars. Fuel Science and Technology International, 13, 807-818. http://dx.doi.org/10.1080/08843759508947707

[4] de Aragão, B.J.G. and Messaddeq, Y. (2008) Peak Separation by Derivative Spectroscopy Applied to FTIR Analysis of Hydrolyzed Silica. Journal of the Brazilian Chemical Society, 8, 1582-1594. http://dx.doi.org/10.1590/S0103-50532008000800019

[5] Ramaswamy, K. and Venkatachalapathy, R. (2006) Infrared Spectroscopic Study of Neyveli Lignite Samples from Mine Cut-I and II. Spectroscopy Letters: An International Journal for Rapid Communication, 24, 759-778. http://dx.doi.org/10.1080/00387019108018157

[6] Pretsch, E., Clerc, T., Seibl, J. and Simon, W. (1990) Tabellen zur Strukturaufklärung organischer Verbindungen mit spektroskopischen Methoden. 3. Auflage, Springer-Verlag Berlin Heidelberg, New York.

[7] Ibarra, J., Royo, C., Monzón, A. and Santamaría, J. (1995) Fourier Transform Infrared Spectroscopic Study of Coke Deposits on a $\mathrm{Cr}_{2} \mathrm{O}_{3}-\mathrm{Al}_{2} \mathrm{O}_{3}$ Catalyst. Elsevier Science, 9, 191-196.

[8] Ibarra, J., Muñoz, E. and Moliner, R. (1996) FTIR Study of the Evolution of Coal Structure during the Coalification Process. Journal of Organic Geochemistry, 24, 725-735.

[9] Schmalfeld, J. (2008) Die Veredlung und Umwandlung von Kohle: Technologien und Projekte 1970 bis 2000 in Deutschland. Deutsche Wissenschaftliche Gesellschaft für Erdöl, Erdgas und Kohle e.V.

[10] Oikonomopoulos, I., Perraki, T. and Tougiannidis, N. (2010) FTIR Study of Two Different Lignite Lithotypes from Neocene Achlada Lignite Deposits in Greece. Bulletin of the Geological Society of Greece, 5, 2284-2293.

[11] Chodak, M., Niklińska, M. and Beese, F. (2007) The Use of Near Infrared Spectroscopy to Quantify Lignite-Derived Carbon in Humus-Lignite Mixtures. Journal of Near-Infrared Spectroscopy, 15, 195-200. http://dx.doi.org/10.1255/jnirs.724 